\title{
THE STANDARD TONSILLECTOMY.*
}

\author{
By John Rice Fletcher, M. D.,
}

\section{Chicago.}

The history of operations upon the faucial tonsils is of douhtful credit to our specialty. Up to a few years ago tonsillotomy was universally practiced. Certainly up to as late as 1910 the best European authorities frowned upon tonsillectomy. Since then many have been converted to it. Tonsillotomy still prevails to no inconsiderable extent among us, partly because some operators will not change, but largely because many incompetents undertake this work upon the ground of its simplicity. As a matter of fact, an exquisite tonsillectomy is not beneath the dignity of the most highly gifted surgeon. On the contrary, those familiar with afterresults will doubtless agree with me that the operation requires so much special training that even very able surgeons, as a rule, do not perform it acceptably. This is hardly to be wondered at since, although we have what may be properly called, a standard operation, namely, instrumental dissection, we are by no means of one opinion how it should be done. In other words, the technic is not standardized. Until it has become so, my opening statement must remain true. Have we not a large number of advocates of the finger dissection? If crudeness, great trauma and the danger of infection are not enough to condemn it, certainly ten per cent of failures should. Up to a very recent date there were but two groups: the finger, and the instrumental dissectionists. This may be called the healthy hopeful period, because the instrumentalists were gaining fast. Their work was constantly improving. Not only did each try to excel the other, but also tried to excel his own work. In this frame of mind speed unfortunately stood high in favor, opening the door to the next step,

*Read before the Chicago Laryngological and Otological Society, March 16, 1915. 
the Sluder method. With the utmost deference and respect, not only to the author of this method, whom we all honor for many other reasons, but also to my Chicago colleagues, who are its ardent advocates, I must say that, to my mind, this is a great step backward. Speed is its greatest recommendation. If the speedy removal of the tonsil in its capsule constituted a tonsillectomy, nothing could equal it. A perfect dissection embraces so much more, that there can be nothing like uniformity in a single operator's work with this method. That it is a better operation than a good dissection few will claim; that on an average it fails in ten per cent of cases is admitted. Failure spells the reason for discarding it. One who acquires a good technic with forceps, knife, scissors, and snare does not fail. One case in ten is one case in ten too many. When this becomes the edict of the specialists, the casual operator in this field, be he general surgeon or not, must be bold indeed. Until we have fought our fight to a finish and speak with but one voice, authoritatively, any may infringe who will. For this reason a call to the colors of the two camps who alone are worthy of serious consideration now, the advocates of a perfect dissection and the Sluder method, seems to me timely. When we can agree upon a technic which completely removes the tonsil in its capsule, does not open the aponeturosis of the superior constrictor muscle, does not injure the palatoglossus or palatopharyngeus muscles, which conserves every bit of the membrane reflected over the tonsil, which prevents fusion of the three muscles named and leaves a linear scar in a rudimentary fossa, which does not injure the voice and which lessens greatly the frequency of secondary hemorrhage, we will have achieved the ideal, in the light of our present knowledge. This is not a dream, but is being done uniformly by many who do the instrumental dissection-and I believe uniformly by them alone. I do not wish to be understood as saying that each case by any operator is as good as another by the same operator, but I do mean to say that all cases can be so well done that none of them can be called anything but good. Even those engaged in the correction of speech defects can have no objection.

I will give you in detail the technic of an instrumental dissection which seems to me to fully accomplish the desirable features enumerated above, without the least insistence upon 
its being absolutely followed. When the last word has been said, each operator will put individuality in his work. This is the art of surgery. Just so long as it is not mechanical, one will excel another. This art can, however, be reduced so nearly to science that, upon the whole, little will be left to be desired, from the present point of view.

In the first place, it is desirable that the operation shall be as bloodless and painless as possible. The first in order that the operator may see every detail. 'The second needs no comment. For the accomplishment of these purposes the following formula will be found good: Cocain hydrochlorat, one grain; adrenalin solution, twenty minims; normal salt solution, eighty minims. Of this not to exceed ten minims to a tonsil may be safely used, as follows: With a hypodermic syringe, the needle of which is bent at an angle of about sixty-five degrees, make blisters under the membrane just as they are made under the conjunctiva in eye operations-first, over the insertion of the anterior pillar; second, at its center; third, just above the mouth of the superior crypt; fourth, at the upper half of the posterior pillar. I use this injection in all cases, both local and general. Its use in hundreds of cases in small children under general anesthesia has not shown bad effect in a single instance.

In local anesthesia a much larger quantity of half of one per cent novocain solution with five drops of adrenalin to the hundred may be thought better. The blisters are made as before, but larger.

Lately, at the suggestion of Dr. Shambaugh, $\mathrm{I}$ have used twenty to thirty minims injected behind the tonsil in addition to the blisters. This seems to give more complete anesthesia. 'The first formula is more useful for blood checking under general anesthesia.

The tonsil is taken hold of only in that part containing the crypt mouths. For this purpose the smallest pattern Tidings forceps have no equal. Their grasp is small, suggesting slight traction. Just enough pull should be made to unfold the nembrane, which, you will remember, passes over the face and posterior border of the anterior pillar, then over the face of the tonsil, making a distinct tuck or fold which extends upward and backward, following the arc of the palatoglossus muscle. There is a distinct demarcation between this mem- 
brane and the tissue through which the crypts open. This line is very closely followed in dissecting the membrane from the tonsil.

Under general anesthesia let your patient lie flat upon an ordinary operating table, mouth well opened and held so with a mouth gag on the patient's right; head turned slightly to the left. Reflect a good light into the throat, inject first one and then the other tonsil, as above described, using the index finger of the left hand as a tongue depressor. Grasp the tonsil and lightly draw it out as above mentioned. Begin the incision at the lowest part of the plica tonsillaris, carry it upward just over the mouth of the superior crypt. Here is a danger point. If the incision is carried too far medialward the outline of the posterior pillar will be changed from an arch to an angle. In other words, it will have been cut, perhaps completely through. If, however, the tonsil is moved in the direction which brings into view the whole of the membrane of the posterior pillar, the incision may be safely carried around this point and downward to the lowest part of the tonsil. Beginning now at the starting point, carry the incision down to meet the other end. This completes the cut. Now free the membrane from the capsule. I usually do this with the back of my knife, which is, as you see, slightly, very slightly, hooked. Enter the fossa by pushing the membrane over the upper pole of the tonsil with the flat or back of the knife blade until the bluish aponeurosis of the superior constrictor is scen. Here begins the blunt dissection. Slightly curved round pointed scissors are used for this purposeSimms' uterine scissors, in fact. With a slight downward and backward push the upper part of the tonsil is freed, in the meantime pulling this part of the tonsil down so that the point of the scissors never goes beyond the sight. The whole anterior portion of the tonsil is now liberated by making a rotary motion with the scissors forward and toward the tongue base, provided it can be done with but little force. If not, the case is not suitable for blunt dissection and must be done with scissors, cutting or rather nipping the adhesions close to the capsule. Two-thirds of the tonsil are now free, making it more movable.

The most painstaking part of the operation remains to be done, namely, the separation of the fibers of the palato- 
pharyngeus muscle from the capsule, into the posterior third of which they are directly inserted. 'This is usually best done by sharp dissection with the scissors, following the capsule very loosely, or even nipping slightly into it rather than in the other direction, as none of the muscle fiber can be spared and they are prone to contract. After this is finished any remaining adhesions at the lowest portion of the tonsil are severed. 'The dissection is complete when the tonsil droops over the pyriform fossa. The snare here shown is now used. Pass the forceps through the loop, taking hold of the upper part of the tonsil, pass the loop over the tonsil, but do not close it while the canula is horizontal. This will certainly take a part of the posterior pillar which you have so carefully saved, and not infrequently take the urula also. If, however, the handle of the snare is lifted upward and the loop is so placed that it cuts from below upward, these faults cannot occur. A loop much larger than the circumference of the thumb joint is dangerous. Any tonsil will go through this size, and the pedicle which it has to cut is about the size of the little finger. When during the dissection a vessel is cut and there is considerable bleeding, tie it with a catgut at once, then proceed. If you wait until the tonsil is out, you may have no little difficulty in firding the bleeding point. The ligature is easily tied when one learns the trick. I would like to call your attention to this snare, the separable ends of which increase its usefulness. The authorized manufacturers are $F$. A. Hardy and Company and V. Mueller and Company.

If I have been overbold in presenting the technic of my operation, I will confess that the ultimate result and praise from others have led me to believe that it has merit. A real desire to add something to the sum total of achievement in our specialty has urged me on. I would not have you think that $I$ regard it as better than all others, but hope it is worthy of your consideration.

In conclusion, allow me to place emphasis on the following points:

First, save all the membrane possible.

Second, make your incision entirely around the tonsil.

Third, employ sharp dissection rather than force, because the weakest tissue will yield to the latter, whether it is muscle or connective tissue. In case of dense adhesions, neither 
blunt dissection, the Sluder instrument nor any modification of it will pass through this tissue by choice. Just in these cases the greatest skill is necessary, and I would remind you that this is acquired by close attention to every case.

Fourth, beware of the posterior pillar. It is here that damage is most frequently done.

Fifth, remember that the snare is not an innocent instrument which cuts always where it should. On the contrary, it will cut just where you place it and will take into its fold all that comes in its way.

Sixth, last and most inportant, see all that you do. If only a few drops.of blood are in the way, have them sponged out. No suction apparatus is necessary. It will be observed. that I use no tongue depressor.

Under local anesthesia there is no difference except that the patient sits before you and no mouth gag is used. 